\title{
Roads Make Loads - Rolling Resistance Saves Emissions
}

\section{Tim Joseph ${ }^{1}$ and Jozef Szymanski ${ }^{2 *}$}

${ }^{1}$ Associate Professor, School of Mining and Petroleum Engineering, University of Alberta, Canada

${ }^{2}$ Professor, School of Mining and Petroleum Engineering, University of Alberta, Canada

In today's global marketplace; where production foci lose ground with unpredictable market changes reacting to a slowing of international demand, as recently seen in China and other fast tracked developing markets of the past half-decade; efficiency has once again reared its head. The cyclic nemesis of manager's courting record production, dormant but alert and alive in the sights of proactive equipment managers, has broken forth advocating predictive maintenance management and consumable control as the spearhead of continued successful resource development. The now aging adage of "care for the asset, production will come" becomes the rekindled anthem as industry remembers that "roads make loads" and "without tires no haulage is done". Once again the notion of research and development seems the right thing to do. The question then is are we ready to take up the call, the challenge, the mantle; to tackle head on the operational issues that until the dollar drops are but shadows of concern. How long before market success outshines the need to concern and we are once again banished to the realms of memory - "something that might have been useful".

We are reminded of the recurring lack of tires, the need to keep rocks off the road, the heat and speed down, the cost, oh the cost! In all of these, where longevity and safety have been the drivers, another appears with perhaps far greater consequences. On the heels of global warming and a $1^{\text {st }}$ cousin to the same, fuel usage and emissions announces itself to the world as a next generation legislative target and control. Surprising or not it seems that this young upstart of a driver also has relations, many of whom are logical but need verification. This is the new direction of operational R\&D to make the case for improved running surfaces. Who would have thought that rolling resistance impacted fuel burn and emissions?

The Northern Canada oil sands mining industry sports running surfaces that behaves very differently under the footprint of ultra class haulers, with capacities now surpassing 480 tons payload at their $20 \%$ overload limit. In winter at $-30^{\circ} \mathrm{C}$ the rolling resistance of an $11 \%$ bitumen content running surface at $6 \%$ delivers hauler fuel usage approaching half that experienced in summer at $12 \%$ rolling resistance on the same surface. In this case we forget that the decreasing viscosity with warming season yields a material that is essentially a sand suspended in a fluid akin to running on a cyclic liquefiable material. This effective doubling of fuel use is not all burnt in the effort to move, but a good proportion is exhausted or bypassed from the increasing tier engine quality striven for by legislators and OEMs; their bid to combat the issue. In truth a tier 3 or 4 engine under such extreme operating conditions, dominated by the geotechnical behaviour of the underfoot, effectively may only perform to the standards of a tier 2 . With the majority of engine $\mathrm{R} \& \mathrm{D}$ proprietary, little is shared and with each mine site different, none provide the same operational performance and few reach OEM targets. The solution may be closer to home. Control the running surface rolling resistance, "roads do make loads", then the burn quality and emissions may have a better chance of reaching target. Based on the initial data and experiences of the handful of R\&D folks that have broached this thought, I would like to share an example estimate for a 400 ton hauler with tier 2 engine (and it is but an example) trend series illustrated in Figure 1 and Figure 2, which show fuel usage and emissions as a function of total resistance (rolling + grade changes).

It should not be surprising that with increased fuel usage there is a corresponding increase in emissions; or that an increase in rolling resistance has the same effect on both. Today's Particulate Matter (PM) controls as with other industry sectors such as coal fired power generation are actually very good and even when a total resistance greater than $15 \%$ is encountered the emissions are still very low. Although the $\mathrm{CO}_{2}$ emissions are not quantified here, it is known that they are proportionate to the rate of $\mathrm{CO}$ release and as such become something of a predictable quantity. What is surprising, or at least for ourselves in this first pass evaluation was the parallel nature of the $\mathrm{NO}_{x}$ and unburnt fuel (HC) emissions, which seemingly matched each other with increasing total resistance.

For example if a 400 ton hauler is consistently operating on an $8 \%$ ramp with $7 \%$ rolling resistance, then this corresponds to a fuel use of 3000 litres per 12 hour shift, $1050 \mathrm{~g} / \mathrm{hr} \mathrm{NO}$ and HC emissions and 1800 $\mathrm{g} / \mathrm{hr} \mathrm{CO}\left(\mathrm{f}\left(\mathrm{CO}_{2}\right)\right)$ emissions. If the surface cap rolling resistance on the

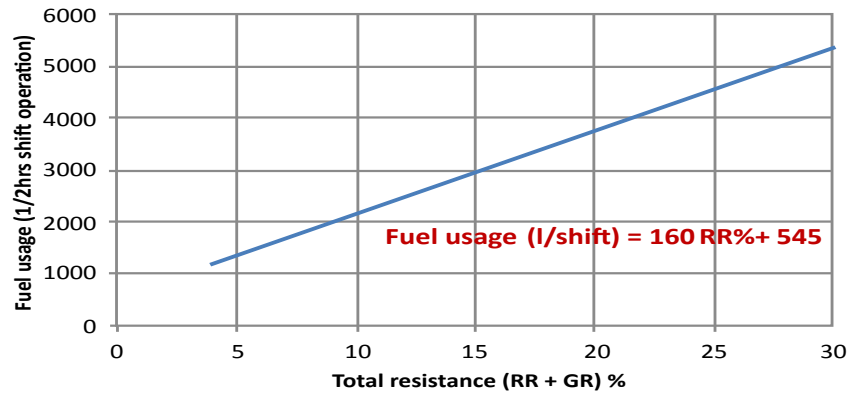

Figure 1: Fuel Usage as a function of total resistance.

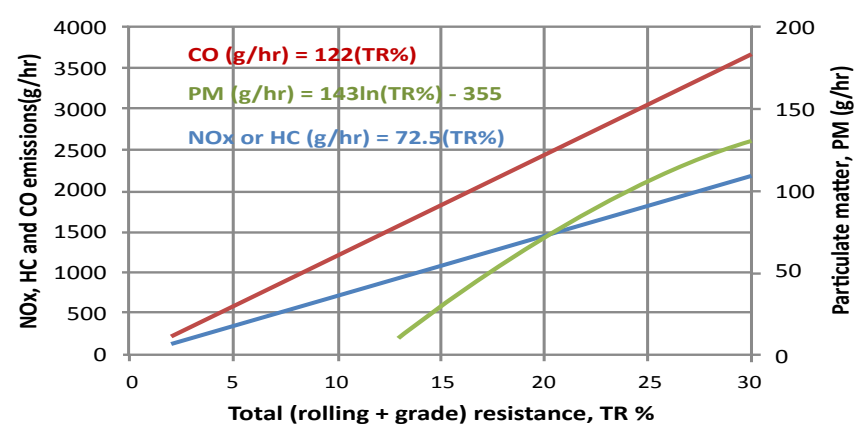

Figure 2: Emission as a function of total resistance.

*Corresponding author: Jozef Szymanski, Professor, School of Mining and Petroleum Engineering, University of Alberta, Canada; Tel: +1-780-492-9770; E-mail: jozef.szymanski@ualberta.ca

Received July 23, 2013; Accepted July 23, 2013; Published July 25, 2012

Citation: Joseph T, Szymanski J (2013) Roads Make Loads - Rolling Resistance Saves Emissions. J Civil Environ Eng 3: e109. doi:10.4172/2165-784X.1000e109

Copyright: ( 2013 Joseph T, et al. This is an open-access article distributed under the terms of the Creative Commons Attribution License, which permits unrestricted use, distribution, and reproduction in any medium, provided the original author and source are credited. 
ramp road is decreased to $5 \%$ (a savings of $2 \%$ ), this corresponds to a decrease in fuel usage of 600 litres per shift and a decrease in emissions of $200 \mathrm{~g} / \mathrm{hr} \mathrm{NO}$ and $\mathrm{HC}$ and $350 \mathrm{~g} / \mathrm{hr} \mathrm{CO}$. In direct fuel costs this approximates to $\$ 350 / \mathrm{shift} / \mathrm{hauler}$. For a fleet of 40 haulers, this is $\$ 14 \mathrm{k}$ per shift or approaching $\$ 7.5 \mathrm{M}$ per year; and we have not even talked about the impact on maintenance or frequency of haul road grading requirements.

The truth is this: Rolling resistance control provides a low hanging fruit grasp on emissions and fuel usage which in turn endorse that "roads do make loads". 